\begin{abstract}
Iranica
Abstracta Iranica Revue bibliographique pour le domaine irano-aryen

Volume 32-33 | 2013

Comptes rendus des publications de 2009-2010
\end{abstract}

\title{
Chuto kenkyu (Etudes du Moyen-Orient). n509, Vol. II
}

Yoko Suzuki

\section{(2) OpenEdition}

1 Journals

Édition électronique

URL : http://journals.openedition.org/abstractairanica/41026

DOI : 10.4000/abstractairanica.41026

ISSN : 1961-960X

\section{Éditeur :}

CNRS (UMR 7528 Mondes iraniens et indiens), Éditions de l'IFRI

\section{Édition imprimée}

Date de publication : 1 décembre 2013

ISSN : 0240-8910

\section{Référence électronique}

Yoko Suzuki, « Chuto kenkyu (Etudes du Moyen-Orient). n509, Vol. II », Abstracta Iranica [En ligne], Volume 32-33 | 2013, document 450, mis en ligne le 01 juillet 2016, consulté le 26 septembre 2020 URL : http://journals.openedition.org/abstractairanica/41026 ; DOI : https://doi.org/10.4000/ abstractairanica. 41026

Ce document a été généré automatiquement le 26 septembre 2020.

Tous droits réservés 


\title{
Chuto kenkyu (Etudes du Moyen- Orient). $\mathrm{n}^{\circ} 509$, Vol. II
}

\author{
Yoko Suzuki
}

\section{RÉFÉRENCE}

Chuto kenkyu (Etudes du Moyen-Orient). Chuto chosakai, 2010/2011, no. 509, vol II, Tokyo, $117 \mathrm{p}$.

1 Ce numéro est la suite du numéro précédent (c.r. $\mathrm{n}^{\circ} 449$ ), spécialement édité à l'occasion du trentième anniversaire de la révolution islamique et celui du début de la guerre Iraq-Iran. Dans ces deux numéros spécialisés, une nouvelle tendance dans l'iranologie au Japon se confirme: une féminisation des chercheurs (K. Yamazaki, K. Sakurai, T. Yamagishi) et leur travail fondé sur les enquêtes de terrain. Si la féminisation est une tendance globale dans le monde académique, la réalisation de nombreuses enquêtes de terrain par elles depuis une quinzaine d'années est le fruit des relations politiques relativement détendues entre les deux pays (Japon Iran) ainsi des changements de moral des femmes japonaises. Ces tendances influencent alors les choix des sujets de recherche qui portent de plus en plus sur l'actualité des mouvements sociaux, notamment concernant les femmes iraniennes.

2 Numéro spécial (vol. 2) : Traces des changements en Moyen-Orient - 20 ans après la crise du Golfe persique, 30 ans après le déclenchement de la guerre Iraq-Iran (Chuto, henka no kiseki-wangan kiki kara 20nen, iran·iraku senso boppatsu kara 30nen) Politique'et relations internationales :

4 Makoto Hachioshi, «La révolution islamique d'Iran dans 'la biographie de Khomeynī' » ('Khomeynī shi den' kara mita iran isurāmu kakumei)

5 Yasushi Kosugi, "Les guerres internationales et internes en Moyen-Orient et leurs relations avec les transformations politiques » (chutoni okeru sensou.naisen to seiji henyou) 
6 Keiko Sakai, «Quelle période de l'ère de Huseyn peut être niée - la guerre Iraq-Iran et la crise du Golfe persique considérées comme le déclencheur du bouillonnement régional » (itsuno'husein jidai ' wo hitei surunoka - konran no, subeteno hajimari toshiteno iran'iraku sensou to wangankiki)

7 Toshihiro Nakayama, « La longue guerre contre l'Iraq » (iraku tono'nagai sensou')

8 Emiko Suzuki, "L'Egypte de Moubarak - les changements au cours de son règne » (mubarāk no ejiputo - sono chisei ni okeru henka)

9 Junji Kawashima, «Les problèmes entrevus dans le mouvement du Sud, 20 ans après l'unification du Yémen » ('nanboku undou'ni miru iemen touitsu 20 nenme no kadai)

10 Chie Ezaki, «Les affaires de sécurité dans les négociations de paix entre l'Israël et la Palestine » (isuraeru-paresuchina wahei koushou ni okeru anzen hoshou mondai)

11 Les femmes et la société :

12 Keiko Sakurai, « Les femmes iraniennes et saoudiennes - possibilités et limites dans la séparation des deux sexes dans l'espace » (iran to saujiarabia no josei-danjo kuukan bunri shakai no kanousei to genkai)

13 Tomoko Yamagishi, « Mouvements citoyens et débats du genre en Iran » (iran ni okeru shimin undou to jendā)

14 Akio Kawai, «Séparation des deux sexes en Arabie Saoudite - contrainte et conflit religieux » (saujiarabia ni okeru danjo bunri).

\section{AUTEURS}

YOKO SUZUKI

Paris 